Romeu Gomes 1

Suely Ferrei ra Deslades 1

Márcia Motta Veiga 1

Carlos Bhering 1

Jacqueline F. C. Santos 1

\section{Por que as crianças são maltratadas? Explicações para a prática de maus-tratos infantis na literatura}

\author{
Why are children abused? \\ A bibliographical review of the explanations \\ for child abuse
}

\footnotetext{
1 Instituto Fernandes Figueira, Fundação Oswaldo Cruz. Av. Rui Barbosa 716 Rio de Janeiro, RJ 22250-020, Brasil. romeu@iff.fiocruz.br
}

\begin{abstract}
This article analyzes the factors related to child abuse that have been published in three of the main Brazilian pediatrics journals. The literature was assessed by content analysis. Fourteen studies were analyzed. The main explanatory factors were: (a) reproduction of violence; (b) family and psychological disorders and alcohol abuse; and (c) the structural or macro-social order. The authors conclude that prevention or intervention policies can be more successful if a theoretical/practical understanding is achieved, and that it is necessary to integrate each unique case with the knowledge based on care for thousands of families involved in child abuse both in Brazil and worldwide.
\end{abstract}

Key words Child Abuse; Child Health; Domestic Violence

Resumo Este artigo tem como obj etivo anal isar os fatores que são i dentificados como atuantes para a ocorrência das situações de maus-tratos cometi dos contra crianças, presentes nos três princi pais periódicos brasileiros de Pediatria. A produção bi bliográfica foi tratada com base na análise de conteúdo. Consi derando os critéri os de inclusão dos artigos, foram anali sados 14 trabalhos. Em termos de resultados, ressal tam-se como model os teóricos expli cativos: (a) a reprodução das experiências de vi ol ência; (b) os desajustes familiares, psíqui cos e al cool ismo; (c) a ordem macro estrutural. Dentre as conclusões, destaca-se que as políticas de prevenção e intervenção dos maus-tratos cometi dos contra a infância terão maior êxi to se conseguirem articular uma compreensão teórico-prática. É preciso integrar a singularidade de cada caso ao conhecimento acumulado no atendi mento a mi lhares de famílias envolvidas na prática de maus-tratos (no Brasil eno mundo).

Palavras-chave Maus-tratos Infantis; Saúdelnfantil; Violência Doméstica 


\section{Introdução}

A violência se constitui atualmente um em dos mais graves problemas de saúde pública. Esse fenômeno se observa no Brasil e em diversos outros países. Segundo Yunes \& Rajs (1994), no período de 1979 a 1990, Brasil, Colômbia e Cuba apresentaram uma tendência francamente crescente da mortalidade por causas externas em todos os grupos de idade, especialmente entre indivíduos de 10 a 24 anos. Segundo os autores, Colômbia, Brasil, Panamá, Porto Rico e Venezuela destacam-se na mortalidade por homicídios ou lesões intencionalmente aplicadas, sobretudo entre jovens e adolescentes. Em nosso país, a violência contra crianças e adolescentes ganha contornos dramáticos. As diversas formas de causas externas são as principais responsáveis pelas mortes de crianças a partir de cinco anos, estendendo à adolescência seus funestos e mortais efeitos.

Contudo, além da violência que leva à morte, convivemos de modo cotidiano e oculto com várias outras formas de vitimação. A violência doméstica ou intrafamilar é, sem dúvida, responsável por milhares de crianças e adolescentes vitimados no Brasil.

Embora não se disponha de dados mais sistemáticos para o país, a implantação da ficha de notificação compulsória dos casos de maustratos pelas Secretarias Municipal e Estadual de Saúde do Rio de Janeiro nos dá pistas dessa magnitude. Somente no período de julho de 1999 a agosto de 2000, foram notificados, pela rede de saúde, 1.061 casos de maus-tratos no Estado (SES-RJ, 2001).

Como observam Minayo \& Souza (1999:8), “até bem pouco tempo, porém, o setor saúde ol hou para o fenômeno da violência, como me ro espectador, um contador de eventos e um re parador dos estragos provocados pel os conflitos sociais". Ainda segundo as autoras, a atuação da área de saúde começa a mudar, timidamente, na década de 60 , quando a pediatria americana passa a identificar a questão dos maustratos contra crianças como um problema clínico-social. Sob a epígrafe de uma síndrome, os maus-tratos, vistos como unicamente acometendo bebês, serão designados como síndrome do bebê espancado e, na década de 70, tornar-se-ão um aspecto a ser considerado pela ação médica. Desse período até o presente momento, inúmeros avanços podem ser registrados, inclusive a própria conceituação que incorpora, na denominação de maus-tratos, crianças de 0 a 12 anos e adolescentes. Entretanto, ainda permanecem certas dificuldades de se tratar a violência como um problema so- cial amplo e como questão que também pertence ao âmbito da saúde. Os desafios continuam atuais: é possível prevenir a violência? Como atuar com as famílias envolvidas na prática de maus-tratos?

Para que se possa caminhar na direção da prevenção dos maus-tratos cometidos contra crianças e adolescentes, um dos aspectos importantes é compreender como essa temática vem sendo explicada no campo da saúde, especialmente na área de saúde infantil. Compreender essa racionalidade é fundamental para que se entendam os obstáculos, resistências às políticas e ações que visam a uma atuação que supere os limites do tratamento biomédico do problema.

Partimos do pressuposto de que a violência possui uma historicidade, assim como as teorias e discursos que se propõem explicá-la. Suas inúmeras manifestações particulares trazem ao debate questões universais, como a importância do valor da vida humana. Suas formas mais permanentes, reproduzidas socialmente de maneira institucionalizada (como os maus-tratos e as violências conjugais), propiciam uma reflexão sobre a intensidade e a dimensão da experiência individual (Deslandes, 2000; Minayo, 1994). Nesse sentido, explicar a ocorrência dos maus-tratos contra as crianças é uma tarefa complexa, na medida em que envolve a articulação em rede de aspectos sócioculturais, psicossociais, psicológicos e até mesmo biológicos, para que se possa atingir uma compreensão mais abrangente acerca da problemática em questão.

Com base nessa perspectiva teórico-explicativa, objetivamos analisar os fatores que são identificados, na produção bibliográfica em Pediatria, nos anos 90, como atuantes para a ocorrência das situações de maus-tratos cometidos contra crianças. Pretendemos, dessa forma, problematizar as idéias mais recorrentes envolvidas nas formulações explicativas desse fenômeno.

\section{Metodologia}

Há inúmeros caminhos para se refletir sobre como os maus-tratos são explicados pelo campo da saúde. Tomamos como referência a análise documental da produção bibliográfica acerca do assunto. Perseguindo a idéia de analisar o estado de arte recente, realizamos um levantamento de revistas nacionais representativas da Pediatria, identificando-se três periódicos, nos anos 90. Em um deles, consideramos os artigos publicados de 1994 a 1997, período de 
existência do periódico, enquanto nos outros dois foram considerados os artigos produzidos no intervalo de 1990 a 1999. Esses periódicos foram escolhidos por dirigirem-se àqueles profissionais que, no campo da saúde, mais têm contato com a faixa etária em estudo e por serem de uma das áreas que mais vêm se preocupando com agravos produzidos pela violência (Gomes et al., 1999; SBP/FIOCRUZ/ MJ, 2000).

Nas três revistas, consideramos todos os artigos que abordavam, especificamente, os maustratos cometidos contra crianças, não sendo incluídos os que abordavam questões relacionadas, simultaneamente, a crianças e adolescentes. Considerando os critérios de inclusão dos artigos, analisamos 14 trabalhos.

A análise do material baseou-se na técnica de análise de conteúdo, segundo sua modalidade "temática". A técnica de análise temática “consiste em descobrir os 'núcl eos de sentido' que compõem a comuni cação e cuja presença, ou freqüência deaparição, podem significar alguma coisa para o objetivo analítico escol hido" (Bardin, 1979:105). Com essa técnica, podemos caminhar, também, na direção da "descoberta do que está por trás dos conteúdos mani festos, indo além das aparências do que está sendo analisado" (Gomes, 2000:74). A análise de conteúdo foi reconduzida basicamente por um recorte interpretativo, cujo escopo hermenêutico abandonou os segmentos de análise estatística (Minayo, 1992).

Tendo como base esses princípios, foram percorridos os seguintes passos de análise: (a) identificação das idéias centrais (núcleos de sentido) das explicações de cada artigo acerca dos maus-tratos; (b) comparação entre as diferentes explicações presentes nos artigos estudados; (c) descoberta de eixos em torno dos quais giravam os argumentos dos autores para explicar os maus-tratos; (d) classificação e discussão dos fatores citados como associados à ocorrência dos maus- tratos cometidos contra a criança.

\section{As explicações sobre os maus tratos contra crianças}

Observarmos, inicialmente, que os fatores identificados, nos artigos analisados, como causadores ou predisponentes e/ ou desencadeantes dos maus- tratos infantis nem sempre são aceitos incondicionalmente por seus autores. Muitas vezes, são situados como revisão bibliográfica da área, tomados, de forma pouco crítica, como o conhecimento acumulado sobre a temática. Nesse caso, retratam o campo consoli- dado como "evidente", no "estoque de referências" de seus estudos. Noutras situações, os autores adotam uma posição de maior protagonismo em face do referencial teórico, conduzindo a pesquisa de acordo com esses modelos ou criticando-os. A análise dos artigos possibilitou-nos, portanto, mapear essas distintas explicações, não sendo nossa intenção vincular este ou aquele autor a qualquer modelo (até mesmo porque os pesquisadores situam diversas referências teóricas).

Para efeito de organização do material, classificamos os artigos segundo o tipo de violência abordado, conforme a Tabela 1. Nessa tabela, observamos que há artigos que abordam os maus-tratos em geral e há outros que tratam de tipos específicos. Os trabalhos relacionados a diversos tipos de maus-tratos, via de regra, situavam essa problemática como uma questão de violência doméstica, uma vez que, segundo eles, grande parte dos agressores era de pais ou parentes. Verificamos que os diferentes fatores que causariam ou influenciariam a ocorrência dos distintos tipos de maustratos estariam presentes em quase todas as suas formas de apresentação, não havendo, em geral, uma explicação específica para um determinado tipo. Os autores que abordam abusos sexuais, além de utilizar as explicações comuns aos outros tipos de maus-tratos, evidenciam o aporte psicológico da questão, como a "pobreza da vida sexual dos pais" envolvidos neste tipo de abuso (Seabra \& Nascimento, 1998; Zavaschi et al., 1991).

A explicação mais recorrente se refere à reprodução das experiências de violência familiar vividas durante a infância, contribuindo para que se perpetuem os maus-tratos. Segundo es-

Tabela 1

Distribuição de artigos publicados em periódico de Pediatria, segundo tipo de maus-tratos, 1990-1999.

\begin{tabular}{ll}
\hline Tipo de violência & Autores \\
\hline Abuso sexual & $\begin{array}{l}\text { Bittencourt (1995), Junqueira (1998), } \\
\text { Seabra \& Nascimento (1998), } \\
\text { Zavaschi et al. (1991) }\end{array}$ \\
Negligência & Davioli \& Ogido (1992) \\
Maus-tratos em geral & $\begin{array}{l}\text { Cariola (1995), Castro Neto (1994), } \\
\text { Centeville et al. (1997), Korn et al. } \\
\text { (1998), Marmo et al. (1995), } \\
\text { Muza (1994), Silva (1998) }\end{array}$ \\
Síndrome da criança espancada & Delgado \& Fisberg (1990) \\
\hline
\end{tabular}


sa lógica, "muitas crianças vítimas de maustratos setornam adultos agressores" (Junqueira, 1998:432). Assim, “os pais reproduzem os modelos de educação na infância" (Cariola, 1995:160), por "terem sofrido os mesmos ti pos de negligência” (Davoli \& Ogido, 1992:406), num cenário de "infâncias difíceis" (Castro Neto, 1994:219).

Até mesmo em relação ao abuso sexual, também se aplica essa lógica. "Pessoas que, quando crianças, foram submetidasa abuso sexual tendem a repetir a situação de abuso com seus filhos" (Zavaschi et al., 1991:133). Relata-se que é comum a conivência de mãe, que se omite em face dos atos de seu companheiro que comete abuso sexual contra a criança porque “geralmente possui história de abuso sexual em sua infância" (Seabra \& Nascimento, 1998:396).

Os argumentos que compõem esse modelo reprodutivo encontram-se ancorados numa abordagem psicológica que deixa transparecer um certo cunho determinista. Nessa perspectiva, os problemas psíquicos e psiquiátricos - fatores emocionais, questões relacionadas com auto-estima e problemas de personalidade em geral da família original - comporiam o universo das vivências que seriam reproduzidas. "Numa família onde toda a estrutura é neurótica, a criança certamente vai 'herdar' este comportamento dos pais" (Centeville et al., 1997:100) e poderá ser um futuro autor de maus-tratos infantis, ao se tornar adulto.

Assim, segundo essa visão, ocorre um círculo vicioso: "as crianças recebem todos os impactos de situações de desajustes, perdendo os seus vínculos afetivos e tornando-se adultos agressi vos, potencializando cada vez mais si tuações agressivas" (Korn et al., 1998:455).

A idéia, expressa nos artigos estudados, de que o presente reedita o passado, em termos de experiências de violência familiar, encontra respaldo em pesquisa realizada com 8.145 famílias (Straus \& Smith, 1995). De acordo com os achados desse estudo, os pais que sofreram violência quando crianças apresentavam um índice de violência contra os seus filhos duas vezes maior do que aqueles que não sofreram violência.

No Brasil, não há pesquisas com a amplitude da investigação norte-americana citada, para que possamos fazer o contraponto entre modelo explicativo e realidade. No entanto, de uma certa forma, podemos relativizar essa ótica com base em um questionamento básico: até que ponto esse círculo vicioso é uma experiência universal que independe do como as diferentes culturas interferem e acomodam as relações entre pais e filhos?
Os estudos tratam de uma probabilidade, uma maior vulnerabilidade, mas não de uma lei inexorável. Como nos lembra Almeida Filho (2000), a transposição de uma idéia de risco epidemiológico, isto é, aquele distribuído numa certa população, não pode ser lido da mesma forma para o risco individual. E aqueles pais que sofreram violência e não abusam de seus filhos? O que os distingue? Essas questões levam-nos a refletir, de um lado, sobre o fato de as diferenças culturais influenciarem na construção de significados distintos em face de uma mesma situação. Por outro lado, o indivíduo e sua família podem ser capazes de administrar as suas vivências violentas, passar por outras vivências que favoreçam à resiliência e adotar comportamentos que as superem. Nesse sentido, apenas um autor reflete que "devese consi derar que as pessoas di spõem de potencial para se reorganizar e incorporar as experiências traumáticas" (Bittencourt,1995:424).

Outra explicação para a existência de crianças mal tratadas se associa à idéia da violência como produto de desajustes familiares, psíquicos e do alcoolismo. Em um artigo, os fatores relacionados a desajustes e problemas psíquicos baseiam-se em dados empíricos de um estudo com 103 vítimas, que apontam os distúrbios comportamentais do agressor (com 31,06\%) e a desagregação familiar (com 21,97\%) como os dois principais fatores desencadeantes da violência (Cariola, 1995).

Nesse modelo, é comum a explicação ser construída com base em uma lógica ancorada numa análise psicológica da personalidade dos agressores. Nesse sentido, as “agressões aparecem quase sempre como decorrência de situações conflitantes efrustrações não resol vidas pelos responsáveis pela criança" (Cariola, 1995: 162).

A exemplo de uma explicação especificamente psicológica do problema, destaca-se uma que se relaciona ao abuso sexual: “o pai pode ter uma personalidade passiva e introvertida e geral mentea vida sexual do casal é pobre. Inicia a relação com sua filha durante um período de 'stress', solidão e dependência. A atividade do incesto pode não ser motivada pelo sexo, mas representa uma necessidade de afeto" (Zavaschi et al., 1991:131).

A negligência também é tratada valendo-se de uma explicação de vertente semelhante: "trata-se geral mente de mães jovens, despreparadas para o casamento (muitas vezes não casadas ou separadas) e para a materni dade. Em geral a gestação não era desejada, a mãe rejeita o bebê, muitas vezes o caçula" (Delgado \& Fisberg, 1990:115). 
O fato de se construir uma explicação psicológica para os maus-tratos com base na análise da personalidade de quem maltrata pode, de certa maneira, apresentar de forma patológica o agressor, que é reprovado, mas compreendido pela sua patologia. Bittencourt (1995: 422) critica essa visão de que o relacionamento adulto-criança seja "concebido como decorrência de traumas secretos do agressor, de sua natureza psicopatológica".

Importante lembrar que os agressores não possuem, necessariamente, perfil de doentes mentais (Deslandes, 1994; Giffin, 1994), tornando-se necessário relativizar sua "classificação patológica" e os conceitos utilizados nessa trajetória. Bentes (1999) questiona a validade da categoria psiquiátrica "distúrbio comportamental". Para a autora, existe uma justaposição de conceitos jurídico-penais e psiquiátricos, utilizados para retratar tanto atos de delinqüência (categoria jurídica descrita na criminologia na década de 30), quanto o distúrbio de comportamento (categoria psiquiátrica da CID 10) (OMS, 1995). Essa classificação do agressor revela mais um julgamento moral pela intensidade da agressão perpetrada do que uma classificação científica.

Outro aspecto a ser criticado é o estigma de desajustadas ou desestruturadas aplicado às famílias que não são organizadas de forma nuclear, com alternância de parceiros da mulhermãe. As mudanças observadas na composição da família brasileira contemporânea dos diferentes segmentos sociais precisam ser mais bem estudadas e levadas em consideração. Essas pesquisas seriam substrato definitivo para relativizar o emprego do rótulo de desestruturação.

Por último, o alcoolismo é apontado também como uma explicação para a ocorrência dos maus-tratos cometidos contra a criança (Bittencourt, 1995; Delgado \& Fisberg, 1990; Seabra \& Nascimento, 1998; Zavaschi et al., 1991). Em geral, esses autores associam a questão do alcoolismo a fatores psicológicos.

Especificamente em relação à negligência, segundo um artigo que analisa essa temática, também "o al coolismo tem uma grande importância, sobretudo ocasi onando violências incontroláveise, no caso de ser crônico, provocando negl igência e abandono dos cuidados com o filho" (Delgado \& Fisberg, 1990:115).

No estudo de Cariola (1995), com 103 vítimas, o alcoolismo figura como o terceiro fator desencadeante de maus-tratos mais importante, com o percentual de $17,42 \%$ no conjunto de todos os fatores.

Em relação a esse tipo de associação, vários estudiosos apontam que o álcool é a substân- cia mais ligada às mudanças de comportamento provocadas por efeitos psicofarmacológicos que desencadeiam a violência. Estudos experimentais (Fagan, 1990, 1993) mostram que o abuso de álcool pode ser responsável pelo aumento da agressividade entre os usuários. Fatores como peso corporal, tipo de metabolismo, processos neuroendócrinos e neuroanatômicos produzem diferenças individuais no uso de drogas e mudança de comportamento.

Entretanto, apesar de evidências empíricas, há muitas dúvidas quanto às explicações causais de uso de álcool e prática de violências, e ainda não foi possível inferir que tal uso afete o comportamento das pessoas envolvidas. Logo, não é possível saber se essas pessoas, em estado de abstinência, teriam cometido as mesmas transgressões. Tampouco é possível discernir se o uso de drogas, estando associado a outros aspectos, desencadeia comportamentos violentos ou se é, por si, um fator causador (M inayo \& Deslandes, 1998).

A ocorrência dos maus-tratos contra a infância também é explicada, na metade dos artigos, para além da mecânica dos eventos, buscando abranger também a ordem macroestrutural que estaria por trás da ocorrência dos maus-tratos. Essa ordem pode ser traduzida por aspectos sociais, econômicos e culturais, como a desi gualdade, a dominação de gênero e de gerações.

Dentro desse modelo explicativo, destacase, inicialmente, o alerta para o próprio conceito de maus-tratos cometidos contra a criança, que deve ser visto como uma noção cuturalmente construída. Isso não descaracteriza a violência do ato, mas mostra que ele é visto como violência a partir da cultura (Junqueira, 1998). Esse alerta aponta para o fato de o próprio conceito ser culturalmente construído, indicando que o que se considera violência em determinadas época e cultura tem significado historicamente delimitado. "Cruel dades cometi das contra crianças pequenas fazem parteda história da humanidade, sem falar do direito de vida ou de morte dado ao pai sobre seus fil hos. Somente em meados do século XIX começa a se esboçar uma preocupação com a criança, que passa a ser encarada como uma pessoa em formação" (Delgado \& Fisberg, 1990:112).

Mesmo sendo entendida, contemporaneamente, como sujeito de direitos, a criança ainda é maltratada por conta da existência de dominação de gênero e de geração. “Essa desigual dade nada mais é do que a assi metria do poder: a submissão do mais fraco pelo mais forte, que se traduz em maus-tratos físicos, em abuso sexual contra meninas e meninos, negli- 
gência e abandono" (Silva, 1998:795). Muitas vezes esses maus-tratos vêm protegi dos sob o manto de medidas educativo-disciplinares. Dentro dessa ótica, a criança deve sempre aprender a obedecer, "sendo que a autoridade do adulto sobre el a assume, muitas vezes, uma configuração autoritária, possi bilitando situações de exercício de poder. Em nome da disciplina e da obediência, criança é maltratada, como no caso do abuso sexual" (Marmo et al., 1995:314).

Destaca-se a noção de que, "ainda que a violência seja um fenômeno universal, ela se torna aci rrada nos países subdesenvolvidos, na medida em que o 'stress' decorrente das dificuldades econômicas das famílias contribui sobre maneira para o seu aparecimento" (Marmo et al., 1995:313-314). Estudo de Cariola (1995:162), com uma amostra de 103 casos, conclui que "a agressão émais evidentena população mais carente, ou seja, com renda de um a três salários mínimos - 52,27\% da amostra, não desprezando o fato da ocorrência de agressões em classes sociais denível maisalto".

A associação entre pobreza e violência, de uma certa forma, encontra-se respaldada pela pesquisa norte-americana anteriormente citada (Straus \& Smith, 1995). Essa pesquisa, ao comparar uma amostra de famílias, observou que naquelas cujo pai estava desempregado havia uma prevalência de maus- tratos contra a criança $50 \%$ maior do que naquelas cujo pai estava empregado.

Essa associação é muito comum nos estudos acerca do assunto e no imaginário social. Concordamos que o aumento dos níveis de miséria constitui fator importante para o crescimento da violência. No entanto, partilhamos da idéia de que tal associação indiscriminada pode gerar uma criminalização da pobreza, colocando segmentos sociais inteiros como suspeitos ou na mira de permanentes julgamentos prévios (Queiroga Neto, 1993). É preciso levarse em conta que existe um viés de notificação, pois as famílias de classes média e alta contam com mecanismos que lhes garantem o sigilo. As famílias mais pobres são também mais numerosas e mais sujeitas à notificação (Deslandes, 1993).

Por outro lado, como no caso do círculo vicioso da violência, em que os agressores agridem porque foram agredidos em sua infância, advertimos sobre o fato de poder reforçar uma associação mecânica entre pobreza e violência, indagando: como explicar o fato de pessoas viverem na pobreza e não praticarem tais violências?

A análise dos artigos revelou que as explicações dos autores, em geral, baseavam-se em uma análise multicausal de maus-tratos. Isso, de uma certa forma, constitui um elemento favorável, embora não suficiente, para que avancemos para uma compreensão mais complexa da temática em questão. Predominou, por exemplo, a junção das explicações sobre a reprodução dos modelos familiares de violência com as explicações psicológicas para o fenômeno. Em segundo lugar, constatamos as associações explicativas entre a reprodução de modelos familiares de violência com os aspectos sócio-culturais. Em minoria, figuram os autores que articulam, em rede, as diversas ordens explicativas, integrando a questão macroestrutural com o psicológico.

Muza (1994), um dos que buscam a análise em rede, reflete que há quatro modelos que explicam a ocorrência dos maus-tratos. Dentro dessa classificação, o comportamento abusivo pode ser explicado como "resultado da interação de forças intrapsíquicas do agressor (modeIo psicodinâmico); como resultado de uma recíproca e contínua interação de determinantes pessoais e ambientais - os filhos aprendem o comportamento agressi vo com os seus pais (modelo da aprendizagem social ); como resul tado da interação entre indivíduo e meio ambiente, enfocando os valores da vítima, do agressor edo meio estressante em que vivem (modelo sóciopsicológico); e, por fim, como resultado da compreensão dos fatores sociais como os principais determinantes do comportamento agressivo (model o sociológico)" (Muza, 1994:58).

O autor destaca, ainda, que, apesar dessa ampla classificação, "nenhum destes model os, isoladamente, explica de forma suficiente a grande quantidade de rel ações agressivas a que estão submetidas inúmeras famílias" (Muza, 1994:58).

\section{Conclusões}

Consideramos que os maus-tratos infantis, por serem atravessados por uma complexidade de fatores, não podem ser explicados por um modelo teórico que sugira uma abordagem determinista ou única sobre o problema. Assim, com base nessa discussão, a primeira desconstrução que precisa ser feita no âmbito dos profissionais de saúde é o reducionismo do assunto. As políticas de prevenção ou intervenção dos maus-tratos cometidos contra a infância provavelmente terão maior êxito se conseguirem caminhar em direção ao confronto dos múltiplos modelos explicativos. Defendemos uma compreensão teórico-prática que articule a singularidade de cada caso ao conhecimento 
acumulado no atendimento de milhares de famílias envolvidas na prática de maus-tratos (no país e no mundo).

Outra conclusão a que chegamos é que ainda precisam ser promovidos estudos para que tenhamos mais dados ancorados na realidade empírica do Brasil. Em geral, os indicadores utilizados na discussão sobre as explicações dos maus-tratos infantis são construídos em ambientes sócio-culturais bem distintos da realidade brasileira. Muito há que se construir para que se afine o foco das políticas públicas que desejem formular princípios para se abordar o assunto em pauta.
Por último, destacamos que, mesmo não tendo como objetivo medir a extensão da produção bibliográfica da área da Pediatria, nos anos 90, no conjunto de três periódicos os maus-tratos foram pouco abordados. Isso revela, de uma certa forma, que essa produção não está conseguindo acompanhar uma das demandas mais atuais no campo da promoção da saúde infantil, que é a de compreender a violência cometida contra esse segmento etário, para que se possam sugerir políticas de atenção e de enfrentamento ao problema.

\section{Referências}

ALMEIDA FILHO, N., 2000. A Ciência da Saúde. São Paulo: Editora Hucitec.

BARDIN, L., 1979. Análise de Conteúdo. Lisboa: Edições 70.

BENTES, A. L. S., 1999. Tudo como Dantes no Quartel D'Abrantes: Estudo das Internações Psiquiátricas de Crianças e Adolescentes através de Encaminhamento Judicial. Dissertação de Mestrado, Rio de Janeiro: Escola Nacional de Saúde Pública, Fundação Oswaldo Cruz.

BITTENCOURT, C. B. F., 1995. Violência sexual contra crianças: Implicações psicológicas. Pediatria Moderna, 31:420-424.

CARIOLA, T. C., 1995. A posição da criança vítima de maus-tratos na constelação familiar. Pediatria Moderna, 31:158-162.

CASTRO NETO, A., 1994. A criança maltratada. Pediatria Moderna, 30:219-227.

CENTEVILLE, M.; CABRAL, M. A. A. \& ATADIA, S. A., 1997. Incidência e tipos mais freqüentes de castigos aplicados pelos pais ou responsáveis de escolares na cidade de Campinas - SP. Pediatria Moderna, 33:99-105.

DAVOLI, A. \& OGIDO, R., 1992. A negligência como forma de violência contra a criança e a importância da atuação médica. Jornal de Pediatria, 68: 405-408.

DELGADO, L. F. \& FISBERG, M., 1990. Síndrome do bebê espancado. Pediatria Moderna, 25:111-116. 
DESLANDES, S. F., 1993. Maus-Tratos na Infância: Um Desafio para o Sistema de Saúde. Análise da Atuação do CRAMI-Campinas. Dissertação de Mestrado, Rio de Janeiro: Escola Nacional de Saúde Pública, Fundação Oswaldo Cruz.

DESLANDES, S. F., 1994. Atenção a crianças e adolescentes vítimas de violência doméstica. Análise de um serviço. Cadernos de Saúde Pública, 10:177187

DESLANDES, S. F., 2000. Violência no Cotidiano dos Serviços de Emergência: Representações, Práticas, Interações e Desafios. Tese de Doutorado, Rio de Janeiro: Escola Nacional de Saúde Pública, Fundação Oswaldo Cruz.

FAGAN, J., 1990. Intoxication and aggression. In: Drugs and Crime (M. Tonry \& J. Q. Wilson, ed.), pp. 8-43, Chicago: Chicago University Press.

FAGAN, J., 1993. Drugs, alcohol and violence. Health Affairs, 12:66-79.

GIFFIN, K., 1994. Violência de gênero, sexualidade e saúde. Cadernos de Saúde Pública, 10:146-155.

GOMES, R., 2000. A análise de dados em pesquisa qualitativa. In: Pesquisa Social: Teoria, Método e Criatividade (M. C. S. Minayo, org.), pp. 67-80, Petrópolis: Editora Vozes.

GOMES, R.; SILVA, C. M. F. P. \& NJAINE, K., 1999. Prevenção à violência contra a criança e o adolescente sob a ótica da saúde: Um estudo bibliográfico. Ciência \& Saúde Coletiva, 4:171-181.

JUNQUEIRA, M. F., 1998. Abuso sexual da criança: Contextualização. Pediatria Moderna, 24:432-436.

KORN, G. P.; CRESPO, A. C. A.; ULSON, G.; CARNEDUTTO, M. D. \& GUTIEREZ, M. T., 1998. Síndrome dos maus-tratos em crianças. Pediatria Moderna, 34:445-460.

MARM O, D. B.; DAVOLI, A. \& OGIDO, R., 1995. Violência doméstica contra a criança. Jornal de Pediatria, 71:313-316.

MINAYO, M. C. S., 1992. O Desafio do Conhecimento. São Paulo: Editora Hucitec/Rio de Janeiro: ABRASCO.

MINAYO, M. C. S., 1994. A violência social sob a perspectiva da saúde pública. Cadernos de Saúde Pública, 10:7-18.

MINAYO, M. C. S. \& DESLANDES, S. F., 1998. A complexidade das relações entre drogas, álcool e violência. Cadernos deSaúde Pública, 14:35-42.
MINAYO, M. C. S. \& SOUZA, E. R., 1999. É possível prevenir a violência? Reflexões a partir do campo da saúde pública. Ciência \& SaúdeColetiva, 4:7-23.

MUZA, G. M., 1994. A criança abusada e negligenciada. Jornal de Pediatria, 70:56-60.

QUEIROGA NETO, A. M., 1993. A internalização da violência. Tempo e Presença, 268:18-21.

OMS (Organização Mundial da Saúde), 1995. Classificação Estatística Internacional de Doenças e Problemas Relacionados à Saúde, 10a Revisão. v. 1. São Paulo: Centro Colaborador da OMS para a Classificação de Doenças em Português.

SBP (Sociedade Brasileira de Pediatria)/FIOCRUZ (Fundação Oswaldo Cruz)/MJ (Ministério da Justiça), 2000. Guia de Atuação Frente a Maus-Tratos na Infância e na Adolescência. Rio de Janeiro: SBP/FIOCRUZ/MJ.

SEABRA, A. S. \& NASCIM ENTO, H. M ., 1998. Abuso sexual na infância. Pediatria Moderna, 34:395415.

SES-RJ (Secretaria Estadual de Saúde do Rio de Janeiro), 2001. Dados sobre Notificações de Maus-Tratos do Estado do Rio de Janeiro. Rio de Janeiro: Programa de Prevenção de Acidentes eViolência, SES-RJ.

SILVA, M. A. S., 1998. Violência contra crianças - Quebrando o pacto do silêncio. Pediatria Moderna, 34:794-797.

STRAUS, M. A. \& SMITH, C., 1995. Family patterns and child abuse. In: Physical Violence in American Families - Risk Factors and Adaptations to Violence in 8.145 Families (M. A. Straus \& R. J. Gelles, ed.), pp. 245-261, New Jersey: Transaction Publishers.

YUNES, J. \& RAJS, D., 1994. Tendencia de la mortalidad por causas violentas en la población general y entre los adolescentes y jóvenes de la región de las Américas. Cadernos de Saúde Pública, 10:88125

ZAVASCHI, M. L. S.; QUINALHA, A. F.; ENK, I.;TELELBON, M. \& DEFAVERY, R., 1991. Abuso sexual em crianças: Uma revisão. Jornal de Pediatria, 67: 130-136.

Recebido em 27 de abril de 2001

Versão final reapresentada em 13 de setembro de 2001 Aprovado em 7 de dezembro de 2001 